\title{
Leptin and adiponectin supplementation modifies mesenteric lymph node lymphocyte composition and functionality in suckling rats
}

\author{
Blanca Grases-Pintó ${ }^{1,2}$, Mar Abril-Gil ${ }^{1,2}$, Maria J. Rodríguez-Lagunas ${ }^{1,2}$, Margarida Castell ${ }^{1,2}$, \\ Francisco J. Pérez-Cano ${ }^{1,2 *}$ and Àngels Franch ${ }^{1,2}$ \\ ${ }^{1}$ Section of Physiology, Department of Biochemistry and Physiology, Faculty of Pharmacy and Food Science, University of \\ Barcelona, 08028 Barcelona, Spain \\ ${ }^{2}$ Nutrition and Food Safety Research Institute (INSA-UB), 08921 Santa Coloma de Gramenet, Spain
}

(Submitted 27 July 2017 - Final revision received 13 November 2017 - Accepted 15 December 2017)

\section{Abstract}

At birth, when immune responses are insufficient, there begins the development of the defence capability against pathogens. Leptin and adiponectin, adipokines that are present in breast milk, have been shown to play a role in the regulation of immune responses. We report here, for the first time, the influence of in vivo adipokine supplementation on the intestinal immune system in early life. Suckling Wistar rats were daily supplemented with leptin $(0.7 \mu \mathrm{g} / \mathrm{kg}$ per $\mathrm{d}, n 36)$ or adiponectin $(35 \mu \mathrm{g} / \mathrm{kg}$ per $\mathrm{d}, n 36)$ during the suckling period. The lymphocyte composition, proliferation and cytokine secretion from mesenteric lymph node lymphocytes (on days 14 and 21), as well as intestinal IgA and IgM concentration (day 21), were evaluated. At day 14, leptin supplementation significantly increased the TCR $\alpha \beta^{+}$cell proportion in mesenteric lymph nodes, in particular owing to an increase in the TCR $\alpha \beta^{+} \mathrm{CD}^{+}$cell population. Moreover, the leptin or adiponectin supplementation promoted the early development $\mathrm{CD}^{+}$cells, with adiponectin being the only adipokine capable of enhancing the lymphoproliferative ability at the end of the suckling period. Although leptin decreased intestinal IgA concentration, it had a trophic effect on the intestine in early life. Supplementation of both adipokines modulated the cytokine profile during (day 14) and at the end (day 21) of the suckling period. These results suggest that leptin and adiponectin during suckling play a role in the development of mucosal immunity in early life.

Key words: Adipokines: Neonatal rats: Intestinal immunity: Breast milk

During human fetal development, the immune system is adapted to the intra-uterine environment ${ }^{(1)}$. The transition from a practically sterile environment in the uterus to the outside world is particularly critical because the neonate is suddenly newly exposed to a large number of micro-organisms and food antigens. Therefore, the development of the human immune system undergoes the most radical and rapid changes. However, during the first months of life, this system is still immature and, in consequence, there are high morbidity and mortality rates owing to infectious diseases ${ }^{(2)}$.

In the human and rat newborn, the immature immune system has significant quantitative and qualitative deficiencies, especially concerning acquired immunity. The underdeveloped acquired immunity is reflected by the existence of low-Ig levels, and the small number of naive $\mathrm{T}$ lymphocytes and antigenpresenting cells in the newborn of both species ${ }^{(3,4)}$. For this reason the survival of the human and rat neonate relies on the innate immune system ${ }^{(5,6)}$. However, this still has some deficiencies, such as low phagocytic activity, defects in neutrophil and monocyte numbers and function, reduced cytokine secretion and lower natural killer (NK) cytotoxic capacity compared with those present in adults ${ }^{(7)}$. On the other hand, physical barriers, such as the intestinal wall, are crucial for the human and rat neonate to avoid infections and control exposure to oral antigens, which in turn is a challenge for the development and maturation of the gut-associated lymphoid tissue (GALT) ${ }^{(4,8)}$. GALT, formed by the inductive sites (Peyer's patches, isolated lymph nodes and mesenteric lymph nodes (MLN)) and the effector sites (intraepithelial and lamina propia lymphocytes), is not mature at birth in both species and develops in the postnatal period ${ }^{(9-11)}$.

In humans, to compensate the immunological immaturity in intra-uterine and early life, the mother provides important factors for protecting the newborn - first, transferring antibodies through the placenta and, later, through the breast milk ${ }^{(12)}$. Human milk contains a wide variety of bioactive factors and hormones $^{(13)}$ including adipokines, such as leptin and adiponectin. The concentrations of these adipokines in breast milk change throughout the lactation ${ }^{(14,15)}$. Leptin and adiponectin are involved in the control of endocrine and metabolic systems

Abbreviations: GALT, gut-associated lymphoid tissue; IFN, interferon; MLN, mesenteric lymph nodes; NK, natural killer; WPC, whey protein concentrate.

* Corresponding author: F. J. Pérez-Cano, fax +34934035 901, email: franciscoperez@ub.edu 
and they seem to play a role in the regulation of the immune system, in both the innate and adaptive immune responses ${ }^{(16,17)}$. In particular, leptin has been described as a pro-inflammatory cytokine that stimulates proliferation and NK cell and T-lymphocyte responses, and the switch to a pro-inflammatory Th1 immunity, thus promoting the secretion of cytokines such as interferon (IFN)- $\gamma$, TNF- $\alpha$, IL-6 and IL- ${ }^{(17)}$. However, the anti- or pro-inflammatory properties of adiponectin are still a matter of discussion $^{(18)}$. It has been described that adiponectin has an anti-inflammatory function because of its capacity to suppress the synthesis of TNF- $\alpha$ and IFN- $\gamma$ and to induce the production of several anti-inflammatory cytokines ${ }^{(19)}$. In contrast, other studies show an inflammatory response under certain circumstances, by activating NK cells and inducing inflammatory cytokines such as IL-1 and IL-6 $6^{(20,21)}$.

To date, there are few data available about the dietary effects of leptin and adiponectin on the GALT, and none about the effect of either adipokines in this compartment in early life, when the development of the immune system is taking place. We hypothesised that these breast milk adipokines, with immunomodulatory actions described in adults, may also play a role in the neonatal immune system, and in particular in the maturation of the GALT. Therefore, the aim of the present study was to evaluate the impact of leptin or adiponectin supplementation on some aspects of the intestinal immune system development in neonatal rats. Specifically, we focused on the MLN lymphocytes, both in terms of their composition and functionality. Thus, immune responses of pups fed leptin or adiponectin at the middle and at the end of the suckling period were established.

\section{Methods}

\section{Animals}

In total, sixteen pregnant Wistar rats (G15) were obtained from Janvier Labs (Le Genest Saint Isle, France) and individually housed in cages under controlled conditions of temperature and humidity in a 12 -h light $-12 \mathrm{~h}$ dark cycle in the Faculty of Pharmacy and Food Science animal's facilities. Rats were fed commercial diet corresponding to the American Institute of Nutrition 93M formulation and water ad libitum.

The studies were performed in accordance with the criteria outlined by the Guide for the Care and Use of Laboratory Animals. Experimental procedures were reviewed and approved by the Ethical Committee for Animal Experimentation of the University of Barcelona (CEEA/UB ref. 220/15).

\section{Experimental design and dietary supplementation}

Pregnant rats were allowed to deliver naturally. The day after birth was registered as day 1 of life. Litters were unified to nine pups per lactating dam, with free access to the nipples and rat diet. Handling was performed in the same time range to avoid the influence of biological rhythms.

According to the oral supplementation given, suckling rats were distributed into four groups ( $n$ 36/group): reference, leptin, adiponectin and whey protein concentrate (WPC). Each group was composed of four litters of nine pups each. The leptin group was administered with $0.7 \mu \mathrm{g} / \mathrm{kg}$ per $\mathrm{d}$ of leptin (i.e. $17 \cdot 6,26 \cdot 6$ and $43 \cdot 8 \mathrm{ng} / \mathrm{rat}$ at days 10,14 and 21 , respectively) (PeproTech ${ }^{\circledR}$ ) in water, based on a reported study ${ }^{(22)}$. Owing to the lack of similar studies, the adiponectin dose was calculated taking into account the concentration ratio of adiponectin $v$. leptin in human milk, which was about fifty times higher $^{(23,24)}$. Therefore, the adiponectin group was supplemented with a solution of $35 \mu \mathrm{g} / \mathrm{kg}$ per $\mathrm{d}$ of adiponectin $\left(\right.$ PeproTech $^{\circledR}$ ) in water (i.e. 0·8, 1.2 and $2 \cdot 1 \mu \mathrm{g} / \mathrm{rat}$ at days 10,14 and 21 , respectively). In parallel, another group of animals was administered with a bovine WPC, containing high concentration of bioactive factors. This WPC was similar to that used in previous studies and it did show immunomodulatory effects on neonatal rats ${ }^{(25,26)}$. Thus, this intervention was used as a possible positive control of modulation by breast milk bioactive factors. Animals from the WPC group were supplemented with Lacprodan ${ }^{\circledR}$ MFGM-10 (Arla Foods Ingredients Group) in a previously described physiological dose for suckling rats receiving infant formula ${ }^{(26)}(0.3 \mathrm{~g} / \mathrm{kg}$ per d) (i.e. $6.9,10 \cdot 8$ and $17.9 \mathrm{mg} / \mathrm{rat}$ at days 10, 14 and 21, respectively). The reference group was administered with the same volume of vehicle (water) as the supplemented groups $(10 \mathrm{ml} / \mathrm{kg}$ per $\mathrm{d})$. To allow gastric emptying, litters were separated from their dam half an hour before oral supplementation. Meanwhile, animals were weighed. Pups received the supplements daily by oral gavage throughout the suckling period (from day 1 to day 21) using low-capacity syringes (Hamilton Bonaduz) adapted to oral 25- or 23-gauge gavage tubes (ASICO), as previously described ${ }^{(25)}$.

Body weight was recorded throughout the study, and on the last day body length (nose-anus) was measured. The body weight gain percentage at a specific day was calculated by subtracting the weight at the beginning of the study (day 1) from the weight at the subsequent days, divided by starting weight and multiplied by 100. These measures enabled the determination of the BMI, calculated as body weight/ length ${ }^{2}\left(\mathrm{~g} / \mathrm{cm}^{2}\right)$, and the Lee index, calculated as $\sqrt[3]{\text { weight }} /$ length $(\sqrt[3]{\mathrm{g}} / \mathrm{cm})$.

\section{Sample collection and processing}

At days 10, 14 and 21, animals were intramuscularly anaesthetised with ketamine $(90 \mathrm{mg} / \mathrm{kg}$ ) (Merial Laboratories S.A.) and xylazine (10 mg/kg) (Bayer A.G.), exsanguinated and MLN and small intestine (SI) were collected. The duodenum was removed and the distal one-third portion of the remaining intestine was used to obtain the gut wash. For this, it was opened lengthwise, cut into 5-mm pieces, weighed and incubated with $2 \mathrm{ml}$ of PBS ( $\mathrm{pH} 7.2 ; 154$ mм sodium chloride ( $\mathrm{NaCl}), 3.99$ mм sodium dihydrogen phosphate monohydrate $\left(\mathrm{NaH}_{2} \mathrm{PO}_{4} \cdot \mathrm{H}_{2} \mathrm{O}\right)$ and $16 \mathrm{~mm}$ disodium hydrogen phosphate dehydrate $\left(\mathrm{Na}_{2} \mathrm{HPO}_{4} \cdot 2 \mathrm{H}_{2} \mathrm{O}\right)$ ) for $15 \mathrm{~min}$ in a shaker ( 55 shakings $/ \mathrm{min}$ ) at $37^{\circ} \mathrm{C}$. After centrifugation $\left(535 \mathrm{~g}, 5 \mathrm{~min}, 4^{\circ} \mathrm{C}\right)$, supernatants were stored at $-20^{\circ} \mathrm{C}$ until $\mathrm{Ig}$ quantification.

\section{Immunoglobulin quantification}

At the end of the suckling period, intestinal IgA and IgM concentrations were quantified in gut wash using a rat IgA or IgM ELISA quantification set (Bethyl Laboratories), as performed in 
previous studies ${ }^{(27)}$. Data are expressed as $\mu$ g of IgA or IgM per gram of intestinal tissue used for the gut wash.

\section{Lymphocyte isolation from mesenteric lymph nodes}

MLN cell suspensions were obtained by passing the tissue through a sterile $40-\mu \mathrm{m}$ mesh cell strainer (Thermo Fisher Scientific). The cell suspension was centrifuged ( $538 \mathrm{~g}, 10 \mathrm{~min}$, $4^{\circ} \mathrm{C}$ ) and resuspended in Roswell Park Memorial Institute (RPMI) 1640 medium (Sigma-Aldrich) enriched with 10\% fetal bovine serum (FBS; Sigma-Aldrich), $100 \mathrm{IU} / \mathrm{ml}$ streptomycin-penicillin (Sigma-Aldrich), $2 \mathrm{~mm}$ L-glutamine (Sigma-Aldrich) and $0.05 \mathrm{~mm}$ $2-\beta$-mercaptoethanol (Merck Millipore). Cell counting and viability were assessed by Countess ${ }^{\mathrm{TM}}$ Automated Cell Counter (Invitrogen $^{\mathrm{TM}}$, Thermo Fisher Scientific). Lymphocytes were immediately used to analyse their phenotype and their ability to proliferate and secrete cytokines after mitogen stimulation.

\section{Lymphocyte immunofluorescence staining and flow cytometry analysis}

Lymphocytes $\left(2-5 \times 10^{5}\right)$ from MLN were stained with anti-rat monoclonal antibodies (mAb) conjugated to fluorescein isothiocyanate (FITC), phycoerythrin (PE), peridinin-chlorophyll-a protein (PercP), allophycocyanin (APC) or APC-cyanine (Cy)7, as in previous studies ${ }^{(28)}$. In this case, the $\mathrm{mAb}$ used were anti$\mathrm{CD} 4$, anti-CD $8 \alpha$, anti-CD $8 \beta$, anti-TCR $\alpha \beta$, anti-TCR $\gamma \delta$, anti-NKRP1A, anti-CD25, anti-CD45RA (BD Biosciences), anti-CD62L and anti-CD103 (Biolegend), anti-TLR-4 (Novus Biologicals) and anti-Foxp3 (eBioscience). The cells were incubated with a mixture of optimal concentrations of mAb in PBS containing $2 \%$ FBS and $0 \cdot 1 \%$ sodium azide (Merck Millipore), for $20 \mathrm{~min}$ at $4{ }^{\circ} \mathrm{C}$ in darkness. A negative control staining using an isotypematched mAb was included in each cell sample. For intracellular staining, cells previously labelled with anti-CD4-PE and anti-CD25-FITC mAb were treated with Foxp3 fixation/permeabilisation kit (eBioscience). Then, intracellular staining with anti-Foxp3-APC mAb was carried out under the same conditions as extracellular staining. All stained cells were fixed with $0.5 \%$ p-formaldehyde and stored at $4{ }^{\circ} \mathrm{C}$ in darkness until analysis by flow cytometry. Analyses were performed using a Gallios $^{\mathrm{TM}}$ flow cytometer (Beckman Coulter Inc.) in the Scientific and Technological Centres of the University of Barcelona (CCiT-UB). All samples were assessed by FlowJo, version 10 software (TreeStar, Inc.). Results are expressed as percentages of positive cells in the lymphocyte population selected according to their forward-scatter characteristics and sidescatter characteristics or in a particular selected population.

\section{Lymphocyte proliferative response}

T-lymphocyte activation was carried out in ninety-six-well plates (TPP) previously coated with anti-CD3/anti-CD28 mAb (10 and $20 \mu \mathrm{g} / \mathrm{ml}$, respectively; BD Biosciences). MLN lymphocytes $\left(10^{5} / 200 \mu \mathrm{l}\right)$ from 14 -d-old and 21 -d-old animals were incubated in quadruplicate with or without stimulus for $48 \mathrm{~h}$. The proliferation was quantified by means of the BrdU Cell Proliferation Assay Kit (Merck Millipore) according to the manufacturer's instructions. This assay is based on the measurement of 5-bromo-2'-deoxyuridine (BrdU) incorporated into proliferating cells during DNA synthesis. After stopping the enzymatic reaction, the absorbance (Ab) was measured at $450 \mathrm{~nm}$ on a microplate photometer (Labsystems Multiskan MS).

The proliferation rate is expressed, as follows, considering the reference group:

Proliferation rate $=(\mathrm{A} / \mathrm{B})$, where

$$
\begin{gathered}
A=\left[\left(A b_{\text {stimulated cells }}-A b_{\text {non-stimulated cells }}\right) / A b_{\text {non-stimulated cells }}\right]_{\text {supplemented group }} \\
B=\left[\left(A b_{\text {stimulated cells }}-A b_{\text {non-stimulated cells }}\right) / A b_{\text {non-stimulated cells }}\right]_{\text {reference group }}
\end{gathered}
$$

\section{Quantification of cytokine production from mesenteric lymph node lymphocytes}

Supernatants collected after the stimulation process described above were used to quantify cytokine production. Concentrations of IL- $1 \alpha$, IL-2, IL-4, IL-5, IL-10, IL-12p70, IL-13, IL-17A, IFN $-\gamma$ and TNF- $\alpha$ were quantified using ProcartaPlex ${ }^{\circledR}$ Multiplex Immunoassay (eBioscience). In brief, specific magnetic capture beads coded with distinct colours were bound to the analyte of interest. Then it was possible to reveal the specific concentration through different detection antibodies conjugated to PE by the Luminex MAGPIX analyser (Luminex ${ }^{\circledR}$ ) at the CCiT-UB.

The lower limits of detection were as follows: $13 \mathrm{pg} / \mathrm{ml}$ for IL- $1 \alpha ; 2 \cdot 10 \mathrm{pg} / \mathrm{ml}$ for IL-2; $0 \cdot 85 \mathrm{pg} / \mathrm{ml}$ for IL-4; $1.65 \mathrm{pg} / \mathrm{ml}$ for IL-5; $14 \mathrm{pg} / \mathrm{ml}$ for IL-10; $4.93 \mathrm{pg} / \mathrm{ml}$ for IL- $12 \mathrm{p} 70 ; 3.17 \mathrm{pg} / \mathrm{ml}$ for IL-13; $2 \cdot 61 \mathrm{pg} / \mathrm{ml}$ for IL-17A; $4.35 \mathrm{pg} / \mathrm{ml}$ for IFN- $\gamma$; and $3.08 \mathrm{pg} / \mathrm{ml}$ for TNF- $\alpha$.

\section{Statistical analysis}

Analysis of the data was carried out by the software package IBM Statistical Package for the Social Sciences (SPSS, version 22.0). To assess the homogeneity of variance and the distribution of the results, Levene's and Shapiro-Wilk tests were performed, respectively. Repeated-measures ANOVA using the Bonferroni correction was used to determine the time-related differences in the body weight in each supplementation. For other variables, when there was a normal distribution and equality of variance, conventional one-way ANOVA test followed by the post hoc Bonferroni was performed. The non-parametric Kruskal-Wallis test followed by the post hoc Mann-Whitney $U$ test were used in order to assess significance. Significant differences were established at $P<0 \cdot 05$.

\section{Results}

\section{Growth and morphometry}

Rats' body weight gain, calculated by monitoring from the day after birth and throughout the suckling period, showed no differences among groups (online Supplementary Fig. S1). Morphometric variables such as BMI and Lee index were also evaluated during suckling (Table 1). The age-increasing BMI pattern was not modified by any of the supplementations. However, while the Lee index was not affected by the diets in any of the groups at 10 and $14 \mathrm{~d}$, a decrease was seen at day 21 $(P<0 \cdot 01)$ in all groups (Table 1$)$. 
Table 1. BMI, Lee index, relative small-intestinal (SI) weight and relative SI length in the four groups over the study (days 10 , 14 and 21$) \|$ (Mean values with their standard errors; $n$ 7-15)

\begin{tabular}{|c|c|c|c|c|c|c|c|c|}
\hline & \multicolumn{2}{|c|}{ BMI $\left(\mathrm{g} / \mathrm{cm}^{2}\right)$} & \multicolumn{2}{|c|}{ Lee index $((\sqrt[3]{\mathrm{g}} / \mathrm{cm}) \times 1000)$} & \multicolumn{2}{|c|}{ Relative SI weight (\%) } & \multicolumn{2}{|c|}{ Relative SI length (\%) } \\
\hline & Mean & SEM & Mean & SEM & Mean & SEM & Mean & SEM \\
\hline \multicolumn{9}{|l|}{ Day 10} \\
\hline Reference & 0.3 & 0.0 & 337.4 & $4 \cdot 2$ & $3 \cdot 3$ & 0.1 & $158 \cdot 1$ & $5 \cdot 9$ \\
\hline Leptin & 0.3 & 0.0 & 335.9 & 3.6 & $3 \cdot 2$ & 0.0 & $164 \cdot 8$ & 8.4 \\
\hline Adiponectin & 0.3 & 0.0 & 341.9 & $3 \cdot 2$ & 3.0 & 0.0 & $162 \cdot 1$ & $5 \cdot 4$ \\
\hline WPC & 0.3 & 0.0 & 337.2 & 2.9 & $3 \cdot 2$ & 0.1 & $171 \cdot 0$ & $7 \cdot 7$ \\
\hline \multicolumn{9}{|l|}{ Day 14} \\
\hline Reference & $0.4 \dagger$ & 0.0 & 335.5 & 2.6 & $3 \cdot 3$ & 0.1 & $116 \cdot 4 \dagger$ & 2.4 \\
\hline Leptin & $0.4 \dagger$ & 0.0 & 335.5 & $3 \cdot 1$ & $3.4 \dagger$ & 0.0 & $119 \cdot 1 \dagger$ & $7 \cdot 6$ \\
\hline Adiponectin & $0.4 \dagger$ & 0.0 & 335.4 & $2 \cdot 2$ & 3.3† & 0.0 & $122.3 \dagger$ & $4 \cdot 1$ \\
\hline WPC & $0.4 \dagger$ & 0.0 & $336 \cdot 0$ & 3.6 & 3.4 & 0.1 & $121.8 \dagger$ & $5 \cdot 3$ \\
\hline \multicolumn{9}{|l|}{ Day 21} \\
\hline Reference & $0.4 \dagger$ & 0.0 & $314.5 † \ddagger$ & 3.3 & 4.4†‡ & 0.1 & 86.9†‡ & $2 \cdot 3$ \\
\hline Leptin & $0.4 \dagger$ & 0.0 & 316.3†‡ & $5 \cdot 7$ & $5 \cdot 3^{*} \dagger \ddagger$ & 0.1 & 94.4†‡ & 4.0 \\
\hline Adiponectin & $0.4 \dagger$ & 0.0 & 314.1†‡ & 4.4 & $4 \cdot 6 \dagger \ddagger \S$ & 0.3 & 92.8†‡ & 3.8 \\
\hline WPC & $0.4 \dagger$ & 0.0 & 314.8†‡ & $6 \cdot 2$ & $4.4 † \ddagger \S$ & 0.1 & 96.6†‡ & 3.0 \\
\hline
\end{tabular}

WPC, whey protein concentrate.

Statistical differences: * $P<0.05 v$. reference group; $\dagger P<0.05 v$. same group at day $10 ; \ddagger P<0.05 v$. same group at day $14 ; \S P<0.05 v$. leptin group (ANOVA)

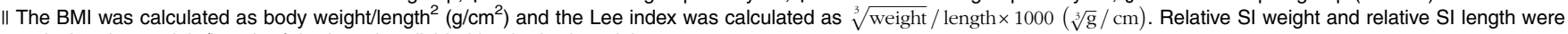
calculated as weight/length of the intestine divided by the body weight $\times 100$.

Although relative weight of the SI, expressed as percentage with respect body weight, increased mainly in the last week of the suckling period (Table 1), the relative length decreased all along this period. Moreover, leptin displayed an intestinal growth-enhancing effect at day $21(P<0.05 v$. reference group).

\section{Intestinal secretory IgA and IgM concentration}

Intestinal secretory IgA and IgM production was established on day 21 (Fig. 1). In the reference group, secretory IgA concentration was five times higher than that of IgM (Fig. 1). Leptin dietary supplementation significantly lowered the secretory IgA content in the intestinal compartment $(P<0 \cdot 01 v$. reference group) (Fig. 1). With regard to IgM, none of the three experimental supplementations modified the levels of this Ig (Fig. 1).

\section{Lymphocyte composition of mesenteric lymph nodes}

A mean count of $2.0 \times 10^{6}\left(\right.$ SEM $\left.2.0 \times 10^{5}\right)$ and $1.3 \times 10^{7}$ (SEM $7 \cdot 6 \times 10^{5}$ ) of MLN cells was established during (day 14) and at the end (day 21) of the suckling period, respectively, from all groups, without differences among them. Their main lymphocyte subset proportions are shown in Table 2. Leptin and WPC supplementations significantly increased the T-cell proportion compared with the reference group at day $14(P<0.01$ and $P<0.05$, respectively). These increases were due to a higher proportion of TCR $\alpha \beta^{+}$cells ( $P<0.01$ and $P<0.05$, respectively), and in particular to an increase in the TCR $\alpha \beta^{+} \mathrm{CD}^{+}$cell population $(P<0.05)$ (Table 2$)$.

Although no significant effects were observed in TCR $\gamma \delta^{+}$cell proportions as a result of adipokine supplementation, an ageincreasing proportion was found in the reference group that was particularly due to the increase in the $\mathrm{TCR} \gamma \delta^{+} \mathrm{CD}^{+}$cell proportion $(P<0 \cdot 01)$. This was not the case for the rest of the groups in which the values observed at day 14 were already as

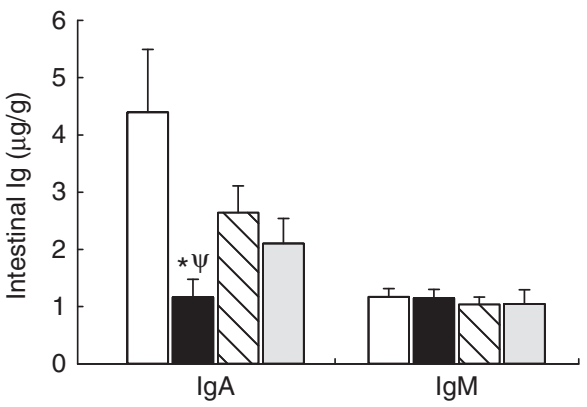

Fig. 1. Supplementation effect on secretory $\lg A$ and $\lg M$ content in the intestinal compartment (gut wash) at the end of the suckling period (day 21) from the four groups: reference $(\square)$, leptin $(\square)$, adiponectin $(\nabla)$ and whey protein concentrate $(\square)$. Values are means ( $n$ 9-12 pups per group analysed in duplicate), with their standard errors represented by vertical bars. Statistical differences: * $P<0.05 \mathrm{~V}$. reference group; $\Psi P<0.05 \mathrm{~V}$. adiponectin group (Mann-Whitney $U$ test).

high as those found on day 21 (Table 2). With regard to NK subset, a relative age-associated decrease was detected between 14- and 21-d-old rats owing to a normal immune development in all groups. This decrease is also found in the proportion of $\mathrm{NK} \mathrm{CD}^{+}$cells in MLN from leptin animals between day 14 and day 21, but not in the others. NK cell percentages at day 14 or at day 21 were not influenced by dietary supplementation. On the other hand, the leptin group showed a decrease from day 14 to day 21 in NKT cell proportion in parallel to a decrease in NKT cells expressing CD8 co-receptor (Table 2).

In reference animals, the whole proportion of $\mathrm{CD}^{+}$cells in MLN increased from day 14 to day 21 of age $(P<0.05)$ (Fig. 2(a)). In contrast, both adipokines induced a higher proportion of $\mathrm{CD}^{+}$ cells on day 14 ( $P<0.05 v$. reference), and on that day they were able to promote the achievement of a percentage of $\mathrm{CD}^{+}$ cells that was typical from day 21 (Fig. 2(a)). When looking at both forms of $\mathrm{CD} 8$ co-receptor $(\mathrm{CD} 8 \alpha \alpha$ and $\mathrm{CD} 8 \alpha \beta)$, 
Table 2. Main lymphocyte subsets in mesenteric lymph nodes in the four groups during (day 14) and at the end (day 21) of the suckling period (Mean values with their standard errors; $n$ 8-14 pups per group analysed in uniplicate)

\begin{tabular}{|c|c|c|c|c|c|c|c|c|}
\hline & \multicolumn{2}{|c|}{ Reference } & \multicolumn{2}{|c|}{ Leptin } & \multicolumn{2}{|c|}{ Adiponectin } & \multicolumn{2}{|c|}{ WPC } \\
\hline & Mean & SEM & Mean & SEM & Mean & SEM & Mean & SEM \\
\hline \multicolumn{9}{|l|}{ Day 14} \\
\hline T cells $(\%)$ & $67 \cdot 6$ & $2 \cdot 0$ & $76 \cdot 4^{\star}$ & 1.9 & $74 \cdot 3$ & $2 \cdot 2$ & $75 \cdot 6^{\star}$ & 1.9 \\
\hline TCRa $\beta^{+}(\%)$ & $65 \cdot 4$ & $2 \cdot 0$ & $74 \cdot 0^{*}$ & $2 \cdot 0$ & $71 \cdot 6$ & $2 \cdot 2$ & $73 \cdot 1^{*}$ & 1.8 \\
\hline $\mathrm{TCR} a \beta^{+} \mathrm{CD}^{+}(\%)$ & 18.4 & 0.8 & $21.9^{\star}$ & 1.3 & $20 \cdot 1$ & 0.9 & $21 \cdot 0^{*}$ & 0.7 \\
\hline $\operatorname{TCR} \gamma \delta^{+}(\%)$ & $2 \cdot 2$ & 0.1 & $2 \cdot 4$ & 0.1 & $2 \cdot 7$ & 0.2 & 2.4 & 0.2 \\
\hline $\mathrm{TCR} \gamma \delta^{+} \mathrm{CD}^{+}(\%)$ & 1.7 & 0.1 & 1.9 & 0.1 & $2 \cdot 0$ & 0.2 & 1.9 & 0.1 \\
\hline Th (\%) $\left(\mathrm{TCR} a \beta^{+} \mathrm{CD}^{-} \mathrm{CD}^{+}\right)$ & $47 \cdot 0$ & 1.5 & 51.0 & $2 \cdot 1$ & 51.5 & $2 \cdot 1$ & $52 \cdot 1$ & 1.3 \\
\hline Treg $(\%)$ & - & - & - & - & & & & \\
\hline NK $(\%)$ & 1.2 & 0.1 & 1.6 & 0.3 & 1.2 & 0.1 & 1.3 & 0.1 \\
\hline NK CD8 ${ }^{+}(\%)$ & 0.5 & 0.1 & 0.5 & 0.1 & 0.4 & 0.1 & 0.4 & 0.1 \\
\hline NKT (\%) & 1.6 & 0.2 & $2 \cdot 2$ & 0.3 & 1.7 & 0.2 & 1.8 & $0 \cdot 2$ \\
\hline NKT CD8 ${ }^{+}(\%)$ & 1.0 & 0.1 & 1.4 & 0.2 & 1.0 & 0.1 & $1 \cdot 1$ & 0.1 \\
\hline B (\%) & $18 \cdot 7$ & $1 \cdot 3$ & $16 \cdot 9$ & 1.6 & $16 \cdot 3$ & 1.4 & $16 \cdot 2$ & $1 \cdot 1$ \\
\hline $\mathrm{CD}^{+} \mathrm{CD}^{+}(\%)$ & $2 \cdot 3$ & 0.4 & 2.8 & 0.2 & $2 \cdot 2$ & $0 \cdot 1$ & 2.4 & 0.2 \\
\hline \multicolumn{9}{|l|}{ Day 21} \\
\hline T cells (\%) & $70 \cdot 4$ & $2 \cdot 1$ & $74 \cdot 3$ & 2.5 & 71.8 & $2 \cdot 6$ & $71 \cdot 0$ & $2 \cdot 3$ \\
\hline TCRa $\beta^{+}(\%)$ & 67.5 & $2 \cdot 1$ & 71.9 & $2 \cdot 7$ & $69 \cdot 0$ & $2 \cdot 8$ & $68 \cdot 1$ & $2 \cdot 4$ \\
\hline $\mathrm{TCR} a \beta^{+} \mathrm{CD}^{+}(\%)$ & 19.5 & 0.7 & 21.4 & 1.4 & $21 \cdot 2$ & $1 \cdot 3$ & 21.5 & $1 \cdot 2$ \\
\hline $\mathrm{TCR}_{\gamma} \delta^{+}(\%)$ & $3.0 \ddagger$ & 0.2 & 2.5 & 0.3 & $2 \cdot 8$ & 0.3 & $2 \cdot 8$ & 0.2 \\
\hline $\mathrm{TCR} \gamma \delta^{+} \mathrm{CD}^{+}(\%)$ & $2 \cdot 4 \ddagger$ & 0.2 & 1.9 & $0 \cdot 1$ & $2 \cdot 1$ & $0 \cdot 2$ & $2 \cdot 1$ & 0.2 \\
\hline Th $(\%)\left(\mathrm{TCR} a \beta^{+} \mathrm{CD}^{-} \mathrm{CD}^{+}\right)$ & $48 \cdot 0$ & 1.5 & $50 \cdot 5$ & 1.6 & 47.9 & 1.6 & $46 \cdot 7 \ddagger$ & $1 \cdot 7$ \\
\hline Treg $(\%)$ & $4 \cdot 2$ & 0.2 & 4.4 & 0.2 & 4.6 & 0.2 & $4 \cdot 1$ & 0.3 \\
\hline NK (\%) & $0.9 \ddagger$ & 0.1 & $0.7 \ddagger$ & 0.1 & $0.8 \ddagger$ & 0.1 & $0.9 \ddagger$ & 0.1 \\
\hline NK CD8 ${ }^{+}(\%)$ & 0.3 & 0.0 & $0.2 \ddagger$ & 0.0 & 0.4 & 0.1 & 0.3 & 0.1 \\
\hline NKT $(\%)$ & 1.7 & 0.2 & $1.3 \ddagger$ & 0.2 & 1.8 & 0.3 & 1.8 & 0.2 \\
\hline NKT CD8 ${ }^{+}(\%)$ & 0.9 & 0.1 & $0.7 \ddagger$ & 0.1 & $1 \cdot 1$ & 0.2 & $1 \cdot 1$ & 0.1 \\
\hline $\mathrm{B}(\%)$ & $17 \cdot 3$ & 1.9 & 13.7 & 1.6 & $17 \cdot 0$ & 1.9 & $16 \cdot 5$ & $1 \cdot 7$ \\
\hline $\mathrm{CD}^{+} \mathrm{CD}^{+}(\%)$ & $2 \cdot 2$ & 0.1 & 2.4 & 0.2 & $2 \cdot 4$ & 0.1 & $2 \cdot 2$ & 0.1 \\
\hline
\end{tabular}

WPC, whey protein concentrate.

Statistical differences: * $P<0.05 \mathrm{v}$. reference group; $\ddagger P<0.05 \mathrm{v}$. same group at day 14 (ANOVA).

a decrease in the $\operatorname{CD} 8 \alpha \alpha^{+}: \mathrm{CD} 8 \alpha \beta^{+}$ratio in the reference and leptin groups was observed in comparison with their respective group at day $14(P<0 \cdot 01)$ (Fig. 2(b)).

The three dietary interventions did not modify the proportion of the other main subpopulations in the MLN compartment, such as Th, Treg, $\mathrm{B}$ and $\mathrm{CD} 8^{+} \mathrm{CD} 4^{+}$cells, either at day 14 or day 21 of life (Table 2). The activation marker CD25 was also studied in the main subsets, and in all cases its percentage was about $4 \%$, without differences among groups or ages studied.

For the study of the intestinal homing, the expression of adhesion molecules CD62L selectin and $\alpha \mathrm{E}$ integrin (CD103) was quantified. CD62L selectin was highly expressed in MLN cells at day 21, whereas $\alpha \mathrm{E}$ integrin was poorly expressed (online Supplementary Fig. S2). No significant differences were detected in the $\mathrm{CD} 62 \mathrm{~L} / \alpha \mathrm{E}$ integrin expression pattern owing to the supplements in any studied group within each studied day (online Supplementary Fig. S2). However, $\alpha \mathrm{E}^{-} \mathrm{CD}_{2} \mathrm{~L}^{+}$cell percentages at day 21 from the reference, leptin and WPC groups (61.5 (SEM 1.7); 60.9 (SEM 1.6); 58.9 (SEm $1 \cdot 3$ ), respectively) were higher than their respective value at day 14 (52.9 (SEM 1.7); 54.5 (SEM 2.6); 50.9 (SEM 1.2), respectively) $(P<0.05)$. In contrast, the adiponectin group showed no differences at days 14 and 21 .

In addition, the expression of $\mathrm{CD} 62 \mathrm{~L}$ selectin/ $\alpha \mathrm{E}$ integrin molecules on $\mathrm{T}$ and $\mathrm{B}$ cells was also studied (online Supplementary Table S1). No significant differences were detected between groups in Th $\left(\mathrm{CD}^{+}{ }^{+} \mathrm{CD} 8^{-}\right)$, Tc $\left(\mathrm{CD}^{+} \mathrm{CD}^{-}\right)$, DP $\left(\mathrm{CD} 4^{+}\right.$ $\left.\mathrm{CD}^{+}\right)$and $\mathrm{B}\left(\mathrm{CD} 45 \mathrm{RA}^{+}\right)$lymphocytes on the same day of analysis, with the exception of the changes found in the $\mathrm{CD}^{+}$ $\mathrm{CD}^{+}$subset at day 21, where leptin and WPC supplementation decreased the $\alpha \mathrm{E}^{+} \mathrm{CD}_{2} \mathrm{~L}^{+}$percentage $(P<0.05 v$. reference). Moreover, some statistical differences between day 14 and day 21 were found in Th and $\mathrm{B}$ subsets within their respective group. In this regard, the low $\alpha \mathrm{E}^{-} \mathrm{CD}_{2} 2 \mathrm{~L}^{+}$cell percentage in the adiponectin group found on day 21 (online Supplementary Fig. S2) could be explained by the relative increase in the percentage of $\mathrm{CD}^{+} \alpha \mathrm{E}^{+} \mathrm{CD}_{2} 2 \mathrm{~L}^{-}$and $\mathrm{CD}^{+} \alpha \mathrm{E}^{+} \mathrm{CD}_{2} 2 \mathrm{~L}^{+}$ (online Supplementary Table S1). Reference, adiponectin and WPC groups, but not the leptin group, showed some age-developmental $\mathrm{CD} 62 \mathrm{~L} / \alpha \mathrm{E}$ integrin changes in the B-cell subset. In Tc cells no differences were found owing to age or supplementations (online Supplementary Table S1).

\section{Mesenteric lymph node lymphocyte proliferation}

To determine the functional capacity of MLN lymphocytes, we studied their lymphoproliferative response on days 14 and 21. At day 14, proliferative capacity was not modified by any supplementation (Fig. 3). At the end of the suckling period, adiponectin and WPC supplementation showed higher lymphoproliferative capacity than the reference group $(P<0.05)$, whereas it was not modified by the leptin supplementation (Fig. 3). 
(a)
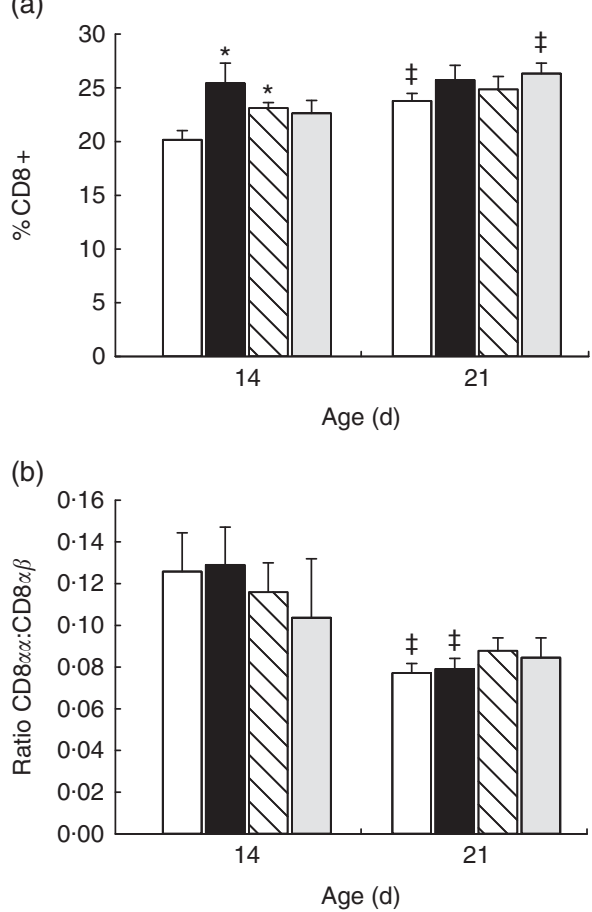

Fig. 2. Percentage of $\mathrm{CD}^{+}$cell subset (a) and CD8aa:CD8aß ratio (b) in mesenteric lymph node lymphocytes during (day 14) and at the end (day 21) of the suckling period from the four groups: reference $(\square)$, leptin $(\square)$, adiponectin $(\Xi)$ and whey protein concentrate $(\square)$. Values are means ( $n$ 9-12 pups per group analysed in uniplicate) with their standard errors represented by vertical bars. Statistical differences: ${ }^{*} P<0.05 \mathrm{v}$. reference group; $\ddagger P<0.05 \mathrm{v}$. same group at day 14 (ANOVA).

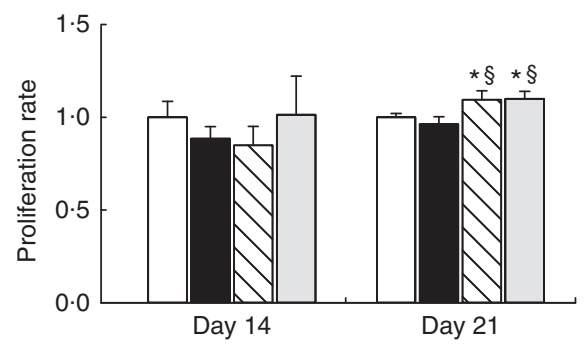

Fig. 3. Supplementation effect on proliferation rate at day 14 and at day 21 in mitogen-stimulated mesenteric lymph nodes (MLN) lymphocytes from the four groups: reference $(\square)$, leptin $(\square)$, adiponectin $(\nabla)$ and whey protein concentrate group $(\square)$. Values are means ( $n$ 3-9 pups per group analysed in quadruplicate), with their standard errors represented by vertical bars. Statistical differences: * $P<0.05 \mathrm{v}$. reference group; $\S P<0.05 \mathrm{v}$. leptin group (Mann-Whitney $U$ test).

\section{Cytokine production by mesenteric lymph node lymphocytes}

The cytokine pattern secreted by MLN cells differed between cells obtained at days 14 and 21 of age (Table 3). Cell culture supernatant from the reference group on day 21 showed lower IL-1 $\alpha$, IL-10, IL-13 and higher TNF- $\alpha$ concentrations than those quantified on day 14 , whereas IL-10/TNF- $\alpha$ was particularly low on day 21 owing to the decrease in IL-10.

All three supplementations showed the same profile as that observed in the reference group for IL-1, IL-10 and IL-10/TNF- $\alpha$. Leptin and adiponectin supplementations were able to lower the levels of IL-13 from day 21 to those observed at day 14 .
Moreover, apart from the reference group, only adiponectin was able to lower TNF- $\alpha$ to the values present at day 14 . In addition, IL- 4 and IL- 5 concentrations at day 21 were lower than those at day 14 in the leptin and adiponectin groups, an effect not observed in the reference group.

At day 14, the leptin supplementation group showed higher IL- 4 and IL- 5 release, being both Th2-related cytokines, than the reference group $(P<0.05)$ (Table 3$)$. In contrast, lymphocytes from the adiponectin group produced significantly higher levels of IL-5, IL-13 and TNF- $\alpha$ at day 14 than the reference group at the same day $(P<0 \cdot 01)$ (Table 3).

At day 21, the leptin and adiponectin groups showed a notable decrease in IL-2 secretion in comparison with the reference group $(P<0 \cdot 01)$. The IL-12p70 secretion was also diminished by the three supplementations $(P<0.05$ in leptin group and $P<0.01$ in adiponectin and WPC $v$. reference group) (Table 3). In addition, IL-13 concentration from animals supplemented with adiponectin was lower than that produced by the reference group $(P<0.01)$.

Overall, the Th1:Th2 cytokine (INF- $\gamma$ :IL-4) ratio was not influenced by age in the reference, adiponectin or WPC groups, and an increase in that ratio at day 21 can only be observed in the leptin group when comparing day 14 and day $21(P<0.05)$ (Table 3).

\section{Discussion}

The neonatal benefits of the presence of leptin and adiponectin in breast milk are many; leptin has an important role in regulation of appetite, growth and weight, and adiponectin was also associated inversely with obesity ${ }^{(15,29)}$. Moreover, both adipokines were described to have immunomodulatory actions $^{(18,30,31)}$. However, at present, there are no studies on the influence of leptin and adiponectin on the immune system in early life, particularly on the immature GALT.

The results of this study show that the adipokine supplementation did not modify the body weight gain pattern, the BMI or the Lee index, suggesting that the administration of leptin and adiponectin did not modify the body mass of the animals. These results are in accordance with other studies performed with rats that were orally administered with leptin during the suckling period ${ }^{(22,32)}$, and also in old male mice receiving subcutaneous doses of leptin ${ }^{(33)}$. Taking into account the role of leptin in satiety and suppression of appetite described in adults $^{(34,35)}$, a weight loss would have been expected. However, studies in rats and mice suggest that leptin may have a different role in neonates because the exogenous administration of leptin to newborn rats modifies the expression of neuropeptides, known to affect appetite in adults, without altering appetite in neonatal rats ${ }^{(36)}$. Furthermore, weight loss has been described as a potent inducer of adiponectin synthesis ${ }^{(37)}$; however, there is almost no information regarding whether adiponectin affects, directly or indirectly, body weight in adults, and none at all regarding neonatal life.

When the adipokines are administered, they travel through the gastrointestinal system and pass through the epithelial barrier into the blood ${ }^{(29)}$. A limitation of this study is that the bioavailability of leptin and adiponectin has not been measured in the suckling rats along the intervention. In addition, although 
Table 3. Cytokine production from mesenteric lymph node lymphocytes in the four groups over the study (days 14 and 21) (Mean values with their standard errors; $n$ 3-12 pups per group analysed in duplicate)

\begin{tabular}{|c|c|c|c|c|c|c|c|c|}
\hline \multirow[b]{2}{*}{ Cytokines (pg/ml) } & \multicolumn{2}{|c|}{ Reference } & \multicolumn{2}{|c|}{ Leptin } & \multicolumn{2}{|c|}{ Adiponectin } & \multicolumn{2}{|c|}{ WPC } \\
\hline & Mean & SEM & Mean & SEM & Mean & SEM & Mean & SEM \\
\hline \multicolumn{9}{|l|}{ Day 14} \\
\hline IL-1a & $24 \cdot 1$ & 8.0 & 34.5 & $10 \cdot 7$ & 50.7 & 5.4 & $18 \cdot 0$ & 5.8 \\
\hline IL-2 & $321 \cdot 2$ & 244.9 & 389.9 & 163.9 & $1540 \cdot 3$ & $732 \cdot 7$ & $1101 \cdot 8$ & 931.8 \\
\hline IL-4 & 108.5 & $18 \cdot 3$ & $225.4^{*}$ & 40.4 & $156 \cdot 6$ & $24 \cdot 2$ & $70.4 \S$ & $5 \cdot 1$ \\
\hline IL-5 & $1 \cdot 3$ & 0.3 & $5 \cdot 1^{\star}$ & 0.9 & $7.7^{*}$ & $2 \cdot 2$ & 1.9 & 0.6 \\
\hline IL-10 & $7147 \cdot 5$ & $1452 \cdot 3$ & $6951 \cdot 3$ & $950 \cdot 8$ & $7916 \cdot 7$ & $1563 \cdot 8$ & $5075 \cdot 1$ & $1493 \cdot 8$ \\
\hline IL-12p70 & $6 \cdot 8$ & 1.4 & 8.6 & $3 \cdot 1$ & $12 \cdot 0$ & 0.9 & 8.6 & 3.1 \\
\hline IL-13 & $30 \cdot 1$ & 9.5 & 54.9 & $17 \cdot 2$ & $85 \cdot 8^{\star}$ & 21.9 & $21 \cdot 0$ & $10 \cdot 0$ \\
\hline IL-17A & 33.1 & $17 \cdot 1$ & $30 \cdot 4$ & 13.4 & 92.8 & $42 \cdot 9$ & 29.5 & 11.8 \\
\hline INF- $\gamma$ & 14314.0 & $8273 \cdot 3$ & 9281.4 & $1495 \cdot 3$ & $14181 \cdot 8$ & 2665.5 & $6059 \cdot 8$ & $1516 \cdot 1$ \\
\hline TNF- $a$ & $6 \cdot 1$ & $1 \cdot 6$ & $6 \cdot 7$ & 2.9 & $16 \cdot 2^{*}$ & $2 \cdot 0$ & 6.9 & $2 \cdot 7$ \\
\hline IL-10/TNF- $a$ & 1943.5 & $710 \cdot 1$ & 1954.4 & 1179.0 & 551.5 & $173 \cdot 3$ & $1148 \cdot 7$ & $546 \cdot 3$ \\
\hline INF- $/ /$ IL-4 & $113 \cdot 2$ & 45.9 & $46 \cdot 0$ & $14 \cdot 2$ & $106 \cdot 9$ & $35 \cdot 7$ & 83.8 & $16 \cdot 0$ \\
\hline \multicolumn{9}{|l|}{ Day 21} \\
\hline IL-1a & $6.5 \ddagger$ & 0.0 & $8 \cdot 2 \ddagger$ & 1.3 & $9.0 \ddagger$ & 1.3 & $7.9 \ddagger$ & 0.7 \\
\hline IL-2 & $716 \cdot 7$ & $210 \cdot 2$ & $54 \cdot 6^{x} \ddagger$ & $6 \cdot 3$ & $120 \cdot 4^{\star} \ddagger$ & 53.9 & $636 \cdot 7$ & $176 \cdot 4$ \\
\hline IL-4 & $86 \cdot 2$ & 9.5 & $50.9 \ddagger$ & 9.4 & $63 \cdot 1 \ddagger$ & $17 \cdot 0$ & 70.4 & $12 \cdot 2$ \\
\hline IL-5 & 1.8 & 0.3 & $1.4 \ddagger$ & 0.5 & $1.3 \ddagger$ & 0.4 & 2.3 & 1.0 \\
\hline IL-10 & $2745 \cdot 8 \ddagger$ & 356.8 & $3060 \cdot 2 \ddagger$ & $613 \cdot 7$ & $1971.0 \ddagger$ & $475 \cdot 7$ & $2084.9 \ddagger$ & $255 \cdot 2$ \\
\hline IL-12p70 & $13 \cdot 8$ & 3.7 & $4 \cdot 3^{*}$ & $1 \cdot 2$ & $2 \cdot 5^{\star} \ddagger$ & 0.0 & $2 \cdot 5^{\star} \ddagger$ & 0.0 \\
\hline IL-13 & 14.0‡ & $2 \cdot 3$ & $7 \cdot 7 \ddagger$ & 2.5 & $6 \cdot 0^{\star} \ddagger$ & 1.4 & 8.4 & 1.4 \\
\hline IL-17A & 58.7 & 11.0 & 45.8 & 8.7 & 37.7 & 8.7 & 64.1 & 10.8 \\
\hline INF- $\gamma$ & $7090 \cdot 1$ & 581.2 & 7407.5 & $853 \cdot 2$ & $7043.1 \ddagger$ & 744.0 & 5424.3 & 375.5 \\
\hline TNF- $a$ & $11.5 \ddagger$ & 1.6 & 8.8 & 0.9 & $8.6 \ddagger$ & 0.5 & 8.9 & 0.5 \\
\hline IL-10/TNF- $a$ & $271 \cdot 7 \ddagger$ & $49 \cdot 1$ & $357.0 \ddagger$ & $72 \cdot 2$ & $232 \cdot 6 \ddagger$ & 51.9 & $231.9 \ddagger$ & $20 \cdot 0$ \\
\hline INF- $\gamma /$ IL-4 & $106 \cdot 1$ & $21 \cdot 1$ & $167 \cdot 1 \ddagger$ & 34.8 & $195 \cdot 2$ & 77.9 & $108 \cdot 6$ & 29.0 \\
\hline
\end{tabular}

WPC, whey protein concentrate group.

Statistical differences: * $P<0.05 \mathrm{v}$. reference group; $¥ P<0.05 \mathrm{v}$. same group at day $14 ; \S P<0.05 \mathrm{v}$. leptin group (ANOVA).

recent studies show that different multimers of adiponectin can have different biological actions ${ }^{(38,39)}$, we supplemented the rats with the monomeric form, whereas the most abundant in human milk is the high-molecular-weight multimeric form ${ }^{(15,40)}$.

However, as they reach the intestine, there must be a direct interaction between these compounds and the intestinal epithelial cells, as well as with the immune cells scattered throughout the intestine (effector sites) or grouped in aggregates (induction sites) of the GALT. For this reason, we considered that it would be interesting to determine the effect of adipokines on morphometric changes of the SI. Supplementation with leptin, but not with adiponectin, for the 3 weeks of suckling was able to increase the relative SI weight, therefore suggesting a certain local trophic effect of leptin on the intestine. However, when we considered the intestinal production of secretory IgA and IgM at the end of the suckling period, the levels were very low, far away from those described in 6-week-old Wistar rats ${ }^{(41)}$, and in agreement with studies showing the immaturity of B cells in the neonate ${ }^{(42)}$. The supplementation with leptin, but not adiponectin, caused a reduction in the secretion of intestinal IgA without affecting IgM levels. These antibodies are produced by plasma cells stimulated under Th2 conditions ${ }^{(43)}$. Some studies suggest the ability of leptin to stimulate Th1 responses and inhibit those of $\mathrm{Th} 2^{(30,44)}$. Thus, the reduction of intestinal secretory IgA associated with leptin supplementation could be attributed to this inhibitory effect. This effect was not observed in the case of adiponectin.
During suckling, rats undergo phenotypical changes in intestinal lymphoid tissues that are a reflection of the maturation of the immune system in this period ${ }^{(4)}$. Therefore, the study of MLN lymphocyte composition and functionality in neonates is a useful strategy for assessing the modulatory ability of leptin and adiponectin on the immune system. In this study, none of the adipokines affected B, NK or NKT populations in MLN lymphocytes. However, leptin significantly increased the proportion of $\mathrm{TCR} \alpha \beta^{+} \mathrm{CD}^{+}$lymphocytes in a similar way to the WPC, suggesting an early maturation of this subset. The increase in the TCR $\alpha \beta^{+} \mathrm{CD}^{+}$cell proportion caused an increase in the overall $\mathrm{T}$-cell percentage. These results are in concordance with a study carried out by Oral et al. ${ }^{(45)}$ in human patients, in which an increase in the percentage of blood T-cells and $\mathrm{CD}^{+}$subsets after leptin intake was found, without changing NK cell percentage. Moreover, another study in mice splenocytes and thymocytes also described an increase in $\mathrm{CD}^{+}$ population after leptin administration ${ }^{(46)}$. This increase in $\mathrm{T}$ lymphocytes induced by leptin could be explained by its suggested anti-apoptotic effect ${ }^{(47)}$. Leptin promotes T-cell survival by modulating the expression of anti-apoptotic proteins such as Bcl-xL in stress-induced apoptosis ${ }^{(48)}$. The reason why this mechanism could be particularly affecting just the $\mathrm{CD}^{+}$ subsets is yet to be established. On the other hand, little is known about the effect of adiponectin on lymphocyte subpopulations. We found here that adiponectin supplementation was also able to increase $\mathrm{CD}^{+}$cell percentage in MLN. This immune-development-promoting effect found here is not in line with the negative regulation effect shown by Wilk et al. ${ }^{(49)}$. 
In particular, they investigated the in vitro and in vivo effects of adiponectin in antigen-specific T-cell responses and evidenced an increase in $\mathrm{CD} 137^{+} \mathrm{CD}^{+}$and $\mathrm{CD} 137^{+} \mathrm{CD} 4^{+}$proportions in adiponectin knockout mice. $\mathrm{CD} 137$ is a co-stimulatory molecule expressed by activated $\mathrm{T}$ cells that enhances $\mathrm{T}$-cell proliferation, IL-2 secretion, survival and cytolytic activity ${ }^{(50)}$.

The proportion of cells bearing the adhesion molecules $\alpha \mathrm{E}$ integrin and CD62L selectin related to the intestinal homing of lymphocytes has been also analysed. The surface $\alpha \mathrm{E}$ integrin was practically non-existent in MLN lymphocytes, and the relative numbers of $\mathrm{CD} 2 \mathrm{~L}^{+}$cells were high and age-related, being higher at the end of lactation. The presence of these molecules, involved in lymphocyte rolling and recruitment to peripheral lymphoid tissues, in early-life rat MLN is similar to that in previous studies ${ }^{(28)}$ and also in older animals ${ }^{(51)}$. The supplementation with either adipokine did not exert profound changes in the expression of these homing molecules with the exception of a decrease in the $\alpha \mathrm{E}^{+} \mathrm{CD}_{2} \mathrm{~L}^{+} \mathrm{CD}^{+} \mathrm{CD}^{+}$percentage in animals supplemented with leptin, the significance of which remains to be explored.

Regarding the MLN cell functionality, although not in this particular tissue, there are previous studies attributing to leptin the capacity to induce lymphoproliferation in vitro and in vivo ${ }^{(17,51-55)}$. In contrast, with respect to the reference group, we found no differences in lymphocytes from animals given leptin. Those animals supplemented with adiponectin had a higher proliferation rate than the reference group and similar values to those animals supplemented with WPC. Thus, it seems that adiponectin is able to accelerate the acquisition of this immune cell capacity in neonatal life. Conversely, Wilk et al. ${ }^{(49)}$ studied the effect of adiponectin on proliferation and apoptosis of antigen-specific $\mathrm{T}$ cells in vitro and showed an apoptosispromoting effect on $\mathrm{CD} 137^{+}$subsets, which was not observed in $\mathrm{CD} 137^{-}$subsets.

The release of cytokines after in vitro stimulation of lymphocytes from leptin- or adiponectin-supplemented animals was also studied. Reported studies with leptin show its ability to stimulate the production of Th1-related cytokines such as IL-1, IL-6, IL-12 and TNF ${ }^{(30)}$. Nevertheless, we found an increase in IL-4 and IL-5, Th2-type cytokines, at day 14 and a decrease of IL-2 and IL-12p70 levels at day 21 owing to leptin supplementation. These results agree with an in vitro study showing that low concentrations of leptin increase IL- 4 production $^{(56)}$. Overall, focusing on the Th1:Th2 cytokine ratio (calculated as IFN- $\gamma$ :IL- 4 ratio), leptin increased the age-related ratio (day $21 \quad v$. day 14 ), thus reinforcing its suggested Th1-promoting and Th2-inhibiting role. In addition, adiponectin increased the release of IL-5, IL-13 and TNF- $\alpha$ at day 14 and decreased the secretion of IL-2, IL-12p70 and IL-13 at day 21. In consequence, it seems that adiponectin does not have a clear Th1/Th2-promoting effect. However, it has been described that adiponectin reduced the expression of the TNF- $\alpha$ in arterial and adipose tissues ${ }^{(57,58)}$. Furthermore, in human monocytederived macrophages, adiponectin inhibits the expression of IL- 6 and TNF- $\alpha$ but increases the levels of IL- $10^{(59)}$. Overall, further studies should be carried out to fully elucidate the contribution of these adipokines to the cytokine secretion in this period of life.
In summary, the results obtained here suggest that dietary supplementation with leptin and adiponectin during the suckling period is able to promote the maturation of the intestinal immune system. A daily supplementation with leptin induces a rise in the intestinal weight and in the proportion of $\mathrm{T}$ cells in MLN, suggesting an intestinal trophic and immunomodulatory effect. Moreover, adiponectin is also able to increase the $\mathrm{CD}^{+}$ percentage and to promote a proliferative response in MLN cells. Both leptin and adiponectin modulate the production of Th1 and Th2 cytokines. This demonstrates the capacity of these adipokines to promote the development and maturation of cells involved in adaptive immune response, which is clearly immature at this stage of life.

\section{Acknowledgements}

The authors thank Maria Guijarro and Lidia Marín-Morote for their help with the laboratory work. The authors also thank Dr J Comas and his laboratory technicians from the Scientific and Technological Centres of the University of Barcelona (CCiT-UB) for their expert assistance in the cytometry service.

This work was supported by a grant from the Spanish Ministry of Economy, Industry and Competitiveness (AGL201348459-P). B.G.-P. holds a fellowship from the Spanish Ministry of Economy, Industry and Competitiveness (BES-2014-068134).

The authors' contributions are as follows: A.F., M.C., F.J.P.-C. and M.J.R.-L. conceived and designed the research; all authors carried out the experiments, the data analysis and were involved in the interpretation of the data; B.G.-P. and F.J.P.-C. contributed to the initial draft of the manuscript; all authors were involved in the critical revision of the manuscript; A.F. and F.J.P.-C. have primary responsibility for the final content. All authors have read and approved the final version of the manuscript for publication.

The authors declare that there are no conflicts of interest.

\section{Supplementary material}

For supplementary material/s referred to in this article, please visit https://doi.org/10.1017/S0007114517003786

\section{References}

1. Szekeres-bartho J (2002) Immunological relationship between the mother and the fetus. Int Rev Immunol 21, 471-495.

2. Palmeira P \& Carneiro-Sampaio M (2016) Immunology of breast milk. Rev Assoc Med Bras 62, 584-593.

3. Schelonka RL1 \& Infante AJ (1998) Neonatal immunology. Semin Perinatol 22, 2-14

4. Pérez-Cano FJ, Franch À, Castellote C, et al. (2012) The suckling rat as a model for immunonutrition studies in early life. Clin Dev Immunol 2012, 537310.

5. Levy O (2007) Innate immunity of the newborn: basic mechanisms and clinical correlates. Nat Rev Immunol 7, 379-390.

6. Wynn JL, Scumpia PO, Winfield RD, et al. (2008) Defective innate immunity predisposes murine neonates to poor sepsis outcome but is reversed by TLR agonists. Blood 112, 1750-1758.

7. Basha S, Surendran N \& Pichichero M (2014) Immune responses in neonates. Expert Rev Clin Immunol 10, 1171-1184. 
8. Chin AM, Hill DR, Aurora M, et al. (2016) Morphogenesis and maturation of the embryonic and postnatal intestine. Semin Cell Dev Biol 66, 81-93.

9. Pérez-Cano FJ, Castellote C, Marín-Gallén S, et al. (2005) Neonatal immunoglobulin secretion and lymphocyte phenotype in rat small intestine lamina propria. Pediatr Res 58, 164-169.

10. Pérez-Cano FJ, Castellote C, González-Castro AM, et al. (2005) Developmental changes in intraepithelial T lymphocytes and NK cells in the small intestine of neonatal rats. Pediatr Res $\mathbf{5 8}$, 885-891.

11. Cornes JS (1965) Number, size, and distribution of Peyer's patches in the human small intestine: Part I The development of Peyer's patches. Gut 6, 225-229.

12. Hanson LA, Korotkova M, Lundin S, et al. (2003) The transfer of immunity from mother to child. Ann NY Acad Sci 987, 199-206.

13. Lönnerdal B (2003) Nutritional and physiologic significance of human milk proteins. Am J Clin Nutr 77, 1537S-1543S.

14. Ozarda Y, Gunes Y \& Tuncer GO (2012) The concentration of adiponectin in breast milk is related to maternal hormonal and inflammatory status during 6 months of lactation. Clin Chem Lab Med 50, 911-917.

15. Newburg DS, Woo JG \& Morrow AL (2010) Characteristics and potential functions of human milk adiponectin. J Pediatr 156, Suppl. 2, S41-S46.

16. Blüher M \& Mantzoros CS (2015) From leptin to other adipokines in health and disease: facts and expectations at the beginning of the 21st century. Metabolism 64, 131-145.

17. Batra A, Okur B, Glauben R, et al. (2010) Leptin: a critical regulator of $\mathrm{CD} 4+\mathrm{T}$-cell polarization in vitro and in vivo. Endocrinology 151, 56-62.

18. Luo Y \& Liu M (2016) Adiponectin: a versatile player of innate immunity. J Mol Cell Biol 8, 120-128.

19. Wolf AM, Wolf $\mathrm{D}$, Rumpold $\mathrm{H}$, et al. (2004) Adiponectin induces the anti-inflammatory cytokines IL-10 and IL-1RA in human leukocytes. Biochem Biophys Res Commun 323, 630-635.

20. Tsatsanis C, Zacharioudaki V, Androulidaki A, et al. (2005) Adiponectin induces TNF-alpha and IL-6 in macrophages and promotes tolerance to itself and other pro-inflammatory stimuli. Biochem Biophys Res Commun 335, 1254-1263.

21. Park PH, McMullen MR, Huang H, et al. (2007) Short-term treatment of RAW264.7 macrophages with adiponectin increases tumor necrosis factor-alpha (TNF-alpha) expression via ERK1/2 activation and Egr-1 expression: role of TNF-alpha in adiponectin-stimulated interleukin-10 production. $J$ Biol Chem 282, 21695-21703.

22. Picó C, Oliver P, Sánchez J, et al. (2007) The intake of physiological doses of leptin during lactation in rats prevents obesity in later life. Int J Obes (Lond) 31, 1199-1209.

23. Weyermann M, Brenner H \& Rothenbacher D (2007) Adipokines in human milk and risk of overweight in early childhood: a prospective cohort study. Epidemiology 18, 722-729.

24. Martin LJ, Woo JG, Geraghty SR, et al. (2006) Adiponectin is present in human milk and is associated with maternal factors. Am J Clin Nutr 83, 1106-1111.

25. Pérez-Cano FJ, Marín-Gallén S, Castell M, et al. (2007) Bovine whey protein concentrate supplementation modulates maturation of immune system in suckling rats. Br J Nutr $\mathbf{9 8}$, Suppl. 1, S80-S84.

26. Pérez-Cano FJ, Marín-Gallén S, Castell M, et al. (2008) Supplementing suckling rats with whey protein concentrate modulates the immune response and ameliorates rat rotavirusinduced diarrhea. J Nutr 138, 2392-2398.

27. Camps-Bossacoma M, Pérez-Cano FJ, Franch À, et al. (2017) Gut microbiota in a rat oral sensitization model: effect of a cocoa-enriched diet. Oxid Med Cell Longev 2017, 7417505 .

28. Rigo-Adrover M, Franch À, Castell M, et al. (2016) Preclinical immunomodulation by the probiotic Bifidobacterium breve $\mathrm{M}-16 \mathrm{~V}$ in early life. PLOS ONE 11, e0166082.

29. Çatlı G, Dündar NO \& Dündar BN (2014) Adipokines in breast milk: an update. J Clin Res Pediatr Endocrinol 6 , 192-201.

30. Naylor C \& Petri WA (2016) Leptin regulation of immune responses. Trends Mol Med 22, 88-98.

31. Carbone F, La Rocca C \& Matarese G (2012) Immunological functions of leptin and adiponectin. Biochimie $\mathbf{9 4}$, 2082-2088.

32. Sánchez J, Oliver P, Miralles O, et al. (2005) Leptin orally supplied to neonate rats is directly uptaken by the immature stomach and may regulate short-term feeding. Endocrinology 146, 2575-2582.

33. Uner AG \& Sulu N (2012) In vivo effects of leptin on lymphocyte subpopulations in mice. Immunobiology 217, 882-888.

34. Ahima RS, Prabakaran D, Mantzoros C, et al. (1996) Role of leptin in the neuroendocrine response to fasting. Nature $\mathbf{3 8 2}$, 250-252.

35. Friedman JM \& Halaas JL (1998) Leptin and the regulation of body weight in mammals. Nature 395, 763-770.

36. Proulx K, Richard D \& Walker CD (2002) Leptin regulates appetite-related neuropeptides in the hypothalamus of developing rats without affecting food intake. Endocrinology 143, 4683-4692.

37. Bruun JM, Lihn AS, Verdich C, et al. (2003) Regulation of adiponectin by adipose tissue-derived cytokines: in vivo and in vitro investigations in humans. Am J Physiol Endocrinol Metab 285, E527-E533.

38. Meilian L \& Feng L (2014) Regulation of adiponectin multimerization, signaling and function. Best Pract Res Clin Endocrinol Metab 28, 25-31.

39. Wang ZV \& Scherer PE (2016) Adiponectin, the past two decades. J Mol Cell Biol 8, 93-100.

40. Savino F, Lupica MM, Benetti S, et al. (2012) Adiponectin in breast milk: relation to serum adiponectin concentration in lactating mothers and their infants. Acta Paediatr Int $J$ Paediatr 101, 1058-1062.

41. Massot-Cladera M, Franch À, Pérez-Cano FJ, et al. (2016) Cocoa and cocoa fibre differentially modulate IgA and IgM production at mucosal sites. Br J Nutr 115 , 1539-1546.

42. Martin R, Nauta AJ, Ben Amor K, et al. (2010) Early life: gut microbiota and immune development in infancy. Benef Microbes 1, 367-382.

43. Adkins B (2007) Heterogeneity in the CD $4 \mathrm{~T}$ cell compartment and the variability of neonatal immune responsiveness. Curr Immunol Rev 3, 151-159.

44. Procaccini C, De Rosa V, Galgani M, et al. (2013) Role of adipokines signaling in the modulation of $\mathrm{T}$ cells function. Front Immunol 4, 332.

45. Oral EA, Javor ED, Ding L, et al. (2006) Leptin replacement therapy modulates circulating lymphocyte subsets and cytokine responsiveness in severe lipodystrophy. J Clin Endocrinol Metab 91, 621-628.

46. Howard JK, Lord GM, Matarese G, et al. (1999) Leptin protects mice from starvation induced lymphoid atrophy and increases thymic cellularity in ob/ob mice. J Clin Invest 104, 1051-1059.

47. Fernández-Riejos P, Najib S, Santos-Alvarez J, et al. (2010) Role of leptin in the activation of immune cells. Mediators Inflamm 2010, 568343. 
48. Fujita Y, Murakami M, Ogawa Y, et al. (2002) Leptin inhibits stress-induced apoptosis of $\mathrm{T}$ lymphocytes. Clin Exp Immunol 128, 21-26.

49. Wilk S, Scheibenbogen C, Bauer S, et al. (2011) Adiponectin is a negative regulator of antigen-activated $\mathrm{T}$ cells. Eur $J$ Immunol 41, 2323-2332.

50. Camps-Bossacoma M, Abril-Gil M, Saldaña-Ruiz S, et al. (2016) Cocoa diet prevents antibody synthesis and modifies lymph node composition and functionality in a rat oral sensitization model. Nutrients $\mathbf{8}, 242$.

51. Abella V, Scotece M, Conde J, et al. (2017) Leptin in the interplay of inflammation, metabolism and immune system disorders. Nat Rev Rheumatol 13, 100-109.

52. Dagogo-Jack S (editor) (2015) Leptin: Regulation and Clinical Applications. New York: Springer International Publishing.

53. Wrann CD, Laue T, Hübner L, et al. (2012) Short-term and long-term leptin exposure differentially affect human natural killer cell immune functions. Am J Physiol Endocrinol Metab 302, E108-E116.
54. Stofkova A (2009) Leptin and adiponectin: from energy and metabolic dysbalance to inflammation and autoimmunity. Endocr Regul 43, 157-168.

55. FitzGerald AJ, Mandir N \& Goodlad RA (2005) Leptin, cell proliferation and crypt fission in the gastrointestinal tract of intravenously fed rats. Cell Prolif 38, 25-33.

56. Fraser DA1, Thoen J, Reseland JE, et al. (1999) Decreased CD4 + lymphocyte activation and increased interleukin-4 production in peripheral blood of rheumatoid arthritis patients after acute starvation. Clin Rheumatol 18, 394-401.

57. Okamoto Y, Kihara S, Ouchi N, et al. (2002) Adiponectin reduces atherosclerosis in apolipoprotein E-deficient mice. Circulation 106, 2767-2770.

58. Maeda N, Shimomura I, Kishida K, et al. (2002) Diet-induced insulin resistance in mice lacking adiponectin/ACRP30. Nat Med 8, 731-737.

59. Kumada M, Kihara S, Ouchi N, et al. (2004) Adiponectin specifically increased tissue inhibitor of metalloproteinase-1 through interleukin-10 expression in human macrophages. Circulation 109, 2046-2049. 